\title{
Predictors of biologic treatment of psoriasis: a non-interventional study
}

This article was published in the following Dove Press journal:

ClinicoEconomics and Outcomes Research

17 February 2014

Number of times this article has been viewed

Luis Puig'

Tao Fan ${ }^{2}$

Qian Ding 2

Nancy E Smith ${ }^{2}$

'Department of Dermatology, Hospital de la Santa Creu i Sant Pau, Universitat Autònoma de Barcelona, Barcelona, Spain; ${ }^{2}$ Global Health

Outcomes, Merck and Co., Inc., USA
Correspondence: Qian Ding

Merck and Co., Inc., PO Box 100, One

Merck Drive, WS2E-76, Whitehouse

Station, NJ 08889, USA

$\mathrm{Tel}+\mid 9084234987$

$\mathrm{Fax}+\mathrm{I} 908735$ I688

Email qian.ding@merck.com
Background: Biologic therapies represent a significant advance in the treatment of psoriasis. However, no studies have examined the patient characteristics predictive of biologic treatment of psoriasis. The purpose of this study was to ascertain the frequency and predictors of treatment of psoriasis with biologics in three European countries, ie, France, Spain, and the UK.

Methods: This was a cross-sectional analysis of physician-recorded demographic and clinical data on patients receiving either conventional or biologic treatments for psoriasis. Data were drawn from the Adelphi 2007 Psoriasis Disease Specific Program (DSP ${ }^{\circledR}$ ), a multinational, real-world survey of patients with psoriasis consulting practicing dermatologists. The numbers of patients treated with biologic and nonbiologic agents were recorded. Data were subjected to bivariate analysis according to treatment regimen (biologic versus nonbiologic). Predictors of treatment with biologics were identified by logistic regression analysis.

Results: A total of 2,509 psoriasis patients were included in this study (1,374 from France, 561 from Spain, and 574 from the UK). Biologic use was most prevalent in Spain $(19.4 \%$ of patients), followed by the UK (9.1\%), and France (8.4\%). In the logistic regression analysis, psoriatic arthritis was a statistically significant predictor of increased biologic use in France (odds ratio [OR] 5.38, 95\% confidence interval [CI] 3.32-8.77), Spain (OR 2.71, 95\% CI 1.16-6.33), and the UK (OR 8.70, 95\% CI 3.65-20.83). Physician-assessed moderate-to-severe disease was also a statistically significant predictor of increased biologic use in France (OR 5.08, 95\% CI 2.01-12.82), Spain (OR 11.11, 95\% CI 4.33-28.57), and the UK (OR 8.55, 95\% CI 1.11-66.67).

Conclusion: In this study, an average of about one tenth of psoriasis patients enrolled in Spain, France, and the UK were treated with biologics in 2007. Physician-assessed moderate-to-severe disease and presence of psoriatic arthritis were significantly associated with biologic use in all three countries.

Keywords: psoriasis, drug therapy, tumor necrosis factor-alpha, antagonists, inhibitors, dermatologic agents, therapeutic use

\section{Introduction}

Psoriasis is a chronic, genetically based, and immune-mediated inflammatory disorder affecting $2 \%-3 \%$ of the Caucasian population in western countries. ${ }^{1}$ These plaques may be localized or widespread across the body. ${ }^{2}$ The fingernails and toenails are involved in $40 \%$ of psoriasis cases, with thickening and/or pitting of the nails as common manifestations..$^{3-5}$

The chronic inflammation underlying psoriasis affects the joints as psoriatic arthritis. The prevalence of psoriatic arthritis among patients with plaque psoriasis 
ranged from $5.9 \%$ to $23.9 \%$ (median $11.2 \%$ ) in eight US and European studies using rheumatologically validated criteria. ${ }^{6}$ Cardiovascular risk factors such as obesity, metabolic syndrome, and hypertension are frequent comorbidities of psoriasis, ${ }^{7-10}$ possibly due to common inflammatory pathways. $^{11}$

In limited (mild) disease, the most commonly used therapy is topical with the addition of phototherapy in refractory cases. In moderate-to-severe psoriasis, phototherapy alone combined with systemic therapy or systemic therapy alone is recommended. Recent guidelines present the level of evidence for the efficacy of the available therapies and give recommendations for their use in daily practice. ${ }^{12}$

Significant advances have been made in the treatment of psoriasis with the availability of biologic therapies. Biologics approved for the treatment of psoriasis in Europe are the tumor necrosis factor-alpha antagonists, ie, infliximab, etanercept, and adalimumab, and the anti-p40 agent, ustekinumab. ${ }^{2}$

European and UK guidelines recommend biologics only for patients with moderate-to-severe psoriasis who have not responded to or are intolerant of conventional therapies. ${ }^{13-17}$ In a recent European consensus, moderate-to-severe psoriasis was defined as a body surface area $>10$ or psoriasis area and severity index (PASI) $>10$ and dermatology life quality index (DLQI) $>10 .{ }^{18}$ The British Association of Dermatologists recommends biologics only for patients who have severe psoriasis, defined as a PASI score $\geq 10$ and a DLQI score $>10 .{ }^{18}$ These criteria are less stringent than those of the UK National Institute for Health and Clinical Excellence for use of infliximab in psoriasis, which recommend infliximab only for very severe psoriasis, defined as a PASI score $\geq 20$ and a DLQI score $>18 .{ }^{19}$

These guidelines provide insight into which patients are eligible for treatment with biologics, but there is little information in the literature about the determinants of treatment of psoriasis with biologics in clinical practice. This study was designed to examine variables associated with biologic treatment in populations of psoriasis patients from France, Spain, and the UK.

\section{Materials and methods}

\section{Study design}

This was a cross-sectional analysis of physician-recorded demographic and clinical data on patients receiving treatment for psoriasis. Data were drawn from the Adelphi 2007 Psoriasis Disease Specific Program $\left(\right.$ DSP $\left.^{\circledR}\right)$, a multinational, real-world survey of patients with psoriasis consulting practicing dermatologists. Physicians were identified from the public lists of health care professionals and were screened for eligibility based on the criteria of whether they were licensed physicians between 1970 and 2006, specialized in dermatology, and actively managing ten or more psoriasis patients per month. Each physician was asked to recruit 8-10 consecutive patients presenting with psoriasis in his/her office. One hundred and forty-three physicians were recruited from France and 61 physicians were recruited from both Spain and the UK $(n=265)$ to complete a detailed patient record form for patients presenting with psoriasis and receiving a prescription for topical agents, phototherapy, or systemic treatment during routine visits in the calendar year 2007. Patients who were 18 years or older and diagnosed as having psoriasis were recruited. Patients who had a missing value for age or gender were excluded from the data analysis.

\section{Variables}

The patient record form included demographics, body mass index, disease symptoms and severity determined by PASI scores, current and previous treatments, patient-reported disease management strategies, the physician's assessment of current severity and severity at diagnosis, the patient's PASI score, and physician-reported reasons for clinical decisions and prescribing. PASI scores were based on the extent of psoriasis in four specific body surface areas (head, trunk, upper limbs, and lower limbs) and the degree of plaque erythema (redness), scaling, and thickness as described by Fredriksson and Pettersson. ${ }^{20}$ The numeric PASI score ranges from 0 (absence of disease) to 72 (maximal disease). The severity of disease was determined from the PASI scores, and the proportions of patients with mild (PASI score $<10$ ) and moderate-to-severe (PASI score $\geq 10$ ) disease. Obesity was defined as a body mass index $\geq 30$. Nonbiologic treatments in this study included topical (eg, corticosteroids, vitamin D3), phototherapy (eg, natural sunlight or ultraviolet A or B irradiation), and traditional systemic (eg, methotrexate, cyclosporine). Biologics in this study included infliximab, etanercept, adalimumab, and efalizumab.

\section{Statistical analysis}

Patient characteristics were analyzed descriptively for the total study samples from each country and then assessed in a bivariate analysis according to treatment with biologics (yes or no). The statistical significance of the distributions across treatment was determined by Student's $t$-test for continuous data (age and PASI score) and by chi-square or Fisher's Exact 
tests for categorical data (sex [male, female], obesity [yes, no], nail involvement [yes, no], and psoriatic arthritis [yes, no]). The availability of PASI scores in the Adelphi database was $<20 \%$, so we developed an algorithm to impute the PASI score for missing values. Potential predictors of the PASI score, ie, severity of body areas affected (11 specific body areas), symptom severity (15 specific symptoms), and percentage of body surface area affected, were introduced stepwise into a multiple fractional polynomial model to derive the polynomials that best predicted the PASI score for each variable. A generalized estimating equations model was used to adjust for clustering of the predictors (severity of body areas affected, symptom severity, and percentage of body surface area affected). After applying this algorithm, the correlation between actual and predicted PASI scores was $R=0.51$.

Physician-assessed severity was classified as mild, moderate, or severe, and the frequencies of each level of severity were determined by country. A chi-square test was used to determine the statistical significance of differences in the frequency distributions. The correlation between PASI scores (measured or imputed) and physician-assessed severity (mild, moderate, or severe) was then assessed by a Spearman analysis in patients for whom both variables were available. We used a logistic regression model to estimate the adjusted odds of receiving treatment with a biologic. Independent variables were age, sex, obesity, physician-assessed severity, PASI score, nail involvement, and psoriatic arthritis (defined as in the descriptive analysis). Finally, the severity of disease was determined from the PASI scores of patients, and the proportions with mild (PASI score <10) and moderate-to-severe (PASI score $\geq 10$ ) disease were compared between patients with psoriatic arthritis and those with psoriasis only. For all analyses, $P<0.05$ was considered to be statistically significant.

\section{Results}

\section{Patient characteristics}

A total of 2,588 patients with psoriasis were included in this study. Seventy-nine patients were excluded due to missing values for age or gender. Finally a total of 2,509 psoriasis patients were included in the statistical analysis (1,374 from France, 561 from Spain, and 574 from the UK, Table 1). The mean age ranged from 42.4 years (Spain) to 46.6 years (France), and men accounted for $52.4 \%$ (UK) to $58.7 \%$ (Spain) of the population. Patients had been diagnosed with psoriasis at a mean of 9.2 (Spain) to 14.8 (UK) years earlier. The mean PASI score ranged from 9.6 (Spain) to 10.4 (UK). The proportion of patients with psoriatic arthritis ranged from $6.2 \%$ (Spain) to $13.0 \%$ (UK). Approximately

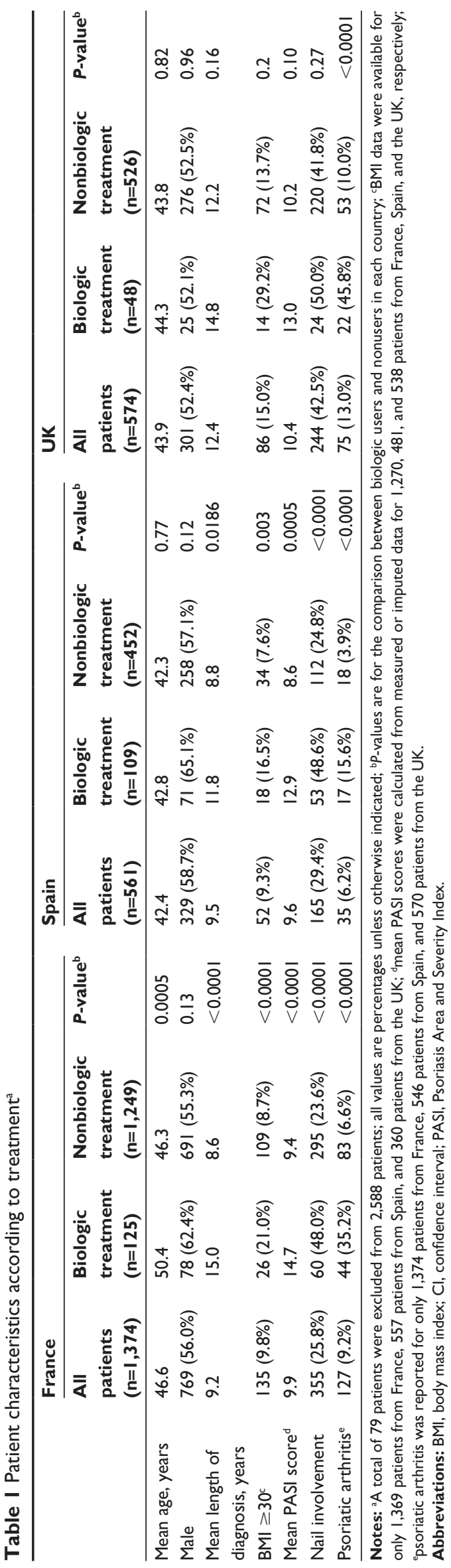


one quarter of patients in France (25.8\%) and Spain (29.4\%) had nail involvement, but the percentage was numerically higher in the UK (42.5\%). In our bivariate assessment of patient characteristics associated with biologic use, psoriatic arthritis was significantly associated with biologic use in all three countries. Obesity, PASI score, and nail involvement were also found to be significantly associated with biologic use in patients from France and Spain.

\section{Patient characteristics associated with biologic use}

Use of biologics was reported in $11.2 \%(n=282)$ of the total patient population (Table 2). Biologic use was most prevalent in Spain (19.4\%), followed by France (9.1\%) and the UK (8.4\%). Among patients with physician-assessed mild disease, biologic use was $8.2 \%$ in France, $12.8 \%$ in Spain, and $7.1 \%$ in the UK (Table 3). Among patients with physician-assessed moderate-to-severe psoriasis, biologic use was $27.8 \%$ in Spain, followed by France (9.7\%) and the UK (9.3\%). Physician-assessed moderate-to-severe disease was also significantly associated with biologic use in all three countries (all comparisons $P<0.0005$ ).

\section{Distribution of psoriasis severity and correlation with PASI score}

The distribution of physician-assessed psoriasis severity varied significantly between countries ( $P<0.001$, Table 4$)$. There were more patients with mild disease than moderate disease and severe disease in Spain $(55.6 \%, 37.6 \%$, and 6.6\%, respectively) and the UK (43.9\%, 39.4\%, and $16.7 \%$, respectively). There were more patients with moderate disease than mild disease and severe disease in France (44.8\%, 40.6\%, and $14.6 \%$, respectively). Physician-assessed psoriasis severity correlated strongly with PASI scores in each country (Spearman coefficient $R=0.699$, Table 5).

\section{Predictors of biologic use}

In the logistic regression analysis (Table 6), psoriatic arthritis was a statistically significant predictor of increased biologic use in France (odds ratio [OR] 5.38, 95\% confidence interval [CI] 3.32-8.77), Spain (OR 2.71, 95\% CI 1.16-6.33), and the UK (OR 8.70, 95\% CI 3.65-20.83). Consistent with this is our finding that patients with psoriatic arthritis had a greater prevalence of PASI score-based moderate-to-severe disease as compared with those patients with psoriasis only (Figure 1).

Physician-assessed moderate-to-severe disease was also a statistically significant predictor of increased biologic use in France (OR 5.08, 95\% CI 2.01-12.82), Spain (OR $11.11,95 \%$ CI 4.33-28.57), and the UK (OR 8.55, 95\% CI 1.11-66.67).

No other variables were consistent across countries, although higher PASI scores increased the odds of using biologics in France (OR 1.05, 95\% CI 1.02-1.08) and Spain (OR 1.02, 95\% CI 1.00-1.05). Obesity was found to be associated with increased odds of biologic use only in France (OR 2.29, 95\% CI 1.33-3.95).

\section{Discussion}

In this study, an average of about one tenth of psoriasis patients enrolled in Spain, France, and the UK were treated with biologics in 2007. The European Medicines Agency requires that only those patients with moderate-to-severe psoriasis and an inadequate response to conventional systemic medications (or adverse effects/contraindication to these agents) are eligible for prescription of biologics in the European Union. ${ }^{13-16}$ The primary caveat to the assessment of patient eligibility for biologic treatment in this study is the lack of information in the Adelphi database on patient history regarding response to conventional therapies. Although a determination of moderate-to-severe disease implies prior therapies had been ineffective, the proportion of patients who had failed to respond to conventional therapies was unknown, and therefore the true percentage of eligible patients cannot be determined. However, the mean PASI score was found to be significantly higher among patients on biologic treatment than in those with nonbiologic treatment in France $(P<0.0001)$ and in Spain

Table 2 Patient treatment by country

\begin{tabular}{lllll}
\hline & $\begin{array}{l}\text { All patients } \\
(\mathbf{n = 2 , 5 0 9 )}\end{array}$ & $\begin{array}{l}\text { France } \\
(\mathbf{n = 1 , 3 7 4 )}\end{array}$ & $\begin{array}{l}\text { Spain } \\
(\mathbf{n = 5 6 1})\end{array}$ & $\begin{array}{l}\text { UK } \\
(\mathbf{n = 5 7 4 )}\end{array}$ \\
\hline Biologic treatment & $282(11.2 \%)$ & $125(9.1 \%)$ & $109(19.4 \%)$ & $48(8.4 \%)$ \\
Nonbiologic treatment & $2,227(88.8 \%)$ & $1,249(90.9 \%)$ & $452(80.6 \%)$ & $526(91.6 \%)$ \\
$\quad$ Topical & $1,257(50.1 \%)$ & $777(56.6 \%)$ & $295(52.6 \%)$ & $185(32.2 \%)$ \\
Phototherapy & $276(11.0 \%)$ & $182(13.2 \%)$ & $31(5.5 \%)$ & $63(11.0 \%)$ \\
Traditional systemic & $694(27.7 \%)$ & $290(21.1 \%)$ & $126(22.5 \%)$ & $278(48.4 \%)$ \\
\hline
\end{tabular}




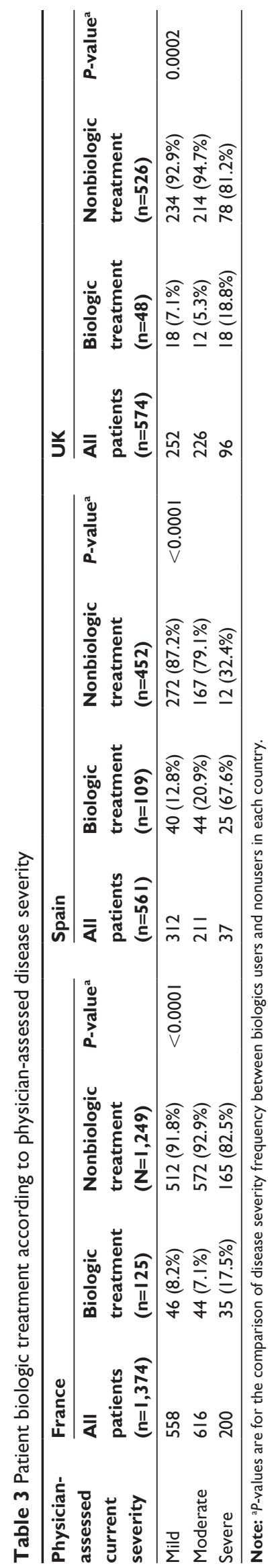

Table 4 Physician-assessed current severity ${ }^{\mathrm{a}}$

\begin{tabular}{llll}
\hline $\begin{array}{l}\text { Physician-assessed } \\
\text { current severity }\end{array}$ & $\begin{array}{l}\text { France } \\
(\mathbf{n}=\mathbf{I}, \mathbf{3 7 4})\end{array}$ & $\begin{array}{l}\text { Spain } \\
(\mathbf{n}=\mathbf{5 6} \mathrm{I})\end{array}$ & $\begin{array}{l}\text { UK } \\
(\mathbf{n}=\mathbf{5 7 4})\end{array}$ \\
\hline Mild & $558(40.6 \%)$ & $312(55.6 \%)$ & $252(43.9 \%)$ \\
Moderate & $616(44.8 \%)$ & $211(37.6 \%)$ & $226(39.4 \%)$ \\
Severe & $200(14.6 \%)$ & $37(6.6 \%)$ & $96(16.7 \%)$ \\
\hline
\end{tabular}

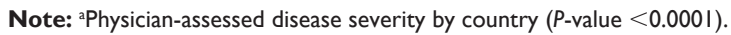

$(P<0.0005)$. There was no significant difference in PASI score between patients with biologic treatment and those with nonbiologic treatment in the UK. In support of our assumption that this determination was accurate is the median PASI score, which was 8.2 (mean 9.5), indicating that nearly $50 \%$ of patients had moderate-to-severe psoriasis on the basis of PASI score. In comparison, 39.0\% of patients with psoriasis had moderate-to-severe disease based on a PASI score $\geq 10$ in a study of patients attending dermatology clinics in Germany. ${ }^{21}$ Similarly, a multinational survey in Eastern Europe found that 37\% of patients had severe disease, defined as a PASI score $\geq 10$ and a DLQI $>10$ (the same as the British Association of Dermatologists' criteria for moderate-to-severe psoriasis), and were thus considered eligible for treatment with biologics. ${ }^{22}$ Determinations of the prevalence of moderate-to-severe psoriasis based on the percentage of body surface area affected are available from the $\mathrm{US}^{23}$ and Canada, ${ }^{24}$ but they vary widely (17\%-95\% of patients) and may not correlate well with PASI-based determinations. However, a survey of California dermatologists in which physician-assessed severity was reported showed that $41 \%$ of psoriasis patients had moderate-to-severe disease. ${ }^{25}$

Large differences between the adjusted OR and unadjusted OR can happen with confounding factors introduced. In this study, greater psoriasis severity, as indicated by PASI score, was not independently associated with biologic treatment. This suggests that European and UK guidelines may not strongly influence treatment decisions. However, physicianassessed severity was found to be a significant predictor of biologic use in all three countries. It is interesting to note that

Table 5 PASI score by physician-assessed current severity ${ }^{\mathrm{a}}$

\begin{tabular}{llll}
\hline $\begin{array}{llll}\text { Physician-assessed } \\
\text { current severity }\end{array}$ & \multicolumn{4}{l}{ Mean PASI score $(\mathbf{n})$} \\
\cline { 2 - 4 } & $\begin{array}{l}\text { France } \\
(\mathbf{n}=\mathbf{I}, \mathbf{2 7 0})\end{array}$ & $\begin{array}{l}\text { Spain } \\
(\mathbf{n}=\mathbf{4 8 0})\end{array}$ & $\begin{array}{l}\text { UK } \\
(\mathbf{n}=\mathbf{5 3 8})\end{array}$ \\
\hline Mild & $5.6(524)$ & $5.8(263)$ & $4.6(240)$ \\
Moderate & $11.0(559)$ & $11.4(18 I)$ & $11.6(206)$ \\
Severe & $18.8(187)$ & $27.9(36)$ & $23.0(92)$ \\
\hline
\end{tabular}

Note: ${ }^{a} R=0.699$ for the Spearman correlation between physician-assessed severity and PASI score.

Abbreviation: PASI, Psoriasis Area and Severity Index. 
Table 6 Predictors of current biologic treatment

\begin{tabular}{|c|c|c|c|c|c|c|}
\hline \multirow[b]{3}{*}{ Increasing age } & \multicolumn{6}{|c|}{ Adjusted odds ratio $(95 \% \mathrm{Cl})^{a}$} \\
\hline & \multicolumn{2}{|c|}{ France $(n=1,266)$} & \multicolumn{2}{|c|}{ Spain $(n=466)$} & \multicolumn{2}{|c|}{ UK $(n=333)$} \\
\hline & 1.00 & $(0.99-1.02)$ & 0.99 & $(0.97-1.00)$ & 0.99 & $(0.96-1.01)$ \\
\hline Female & 0.94 & $(0.62-1.54)$ & 0.79 & $(0.47-1.32)$ & 1.19 & $(0.55-2.57)$ \\
\hline $\mathrm{BMI} \geq 30$ versus $\mathrm{BMI}<30$ & 2.29 & $(1.33-3.95)$ & 1.38 & $(0.62-3.13)$ & 1.81 & $(0.80-4.11)$ \\
\hline Nail involvement & 1.49 & $(0.96-2.32)$ & 1.30 & $(0.76-2.25)$ & 0.90 & $(0.40-2.00)$ \\
\hline Increasing PASI score & 1.05 & $(1.02-1.08)$ & 1.02 & $(1.00-1.05)$ & 1.00 & $(0.95-1.05)$ \\
\hline Moderate-to-severe disease ${ }^{b}$ & 5.08 & $(2.01-12.82)$ & II.II & $(4.33-28.57)$ & 8.55 & $(1.11-66.67)$ \\
\hline Psoriatic arthritis & 5.38 & $(3.32-8.77)$ & 2.71 & $(1.16-6.33)$ & 8.70 & $(3.65-20.83)$ \\
\hline
\end{tabular}

Notes: aBold text indicates statistical significance; ${ }^{b}$ physician-assessed disease severity, moderate and severe patients are combined.

Abbreviations: BMI, body mass index; $\mathrm{Cl}$, confidence interval; PASI, Psoriasis Area and Severity Index.

a subjective assessment of physician severity, which was done by dermatologists presumably familiar with the diagnosis and management of psoriasis, was found to be a significant predictor, and not PASI score, which is an objective measure. A physician's severity assessment may be driving the treatment decision to prescribe biologics rather than an objective measure in clinical practice. However, the lack of association might speak to the imputation method used to calculate PASI score for those patients where it was missing.

The PASI index does not specifically include nail psoriasis or the presence of psoriatic arthritis, which may reflect greater disease severity. Although these other variables

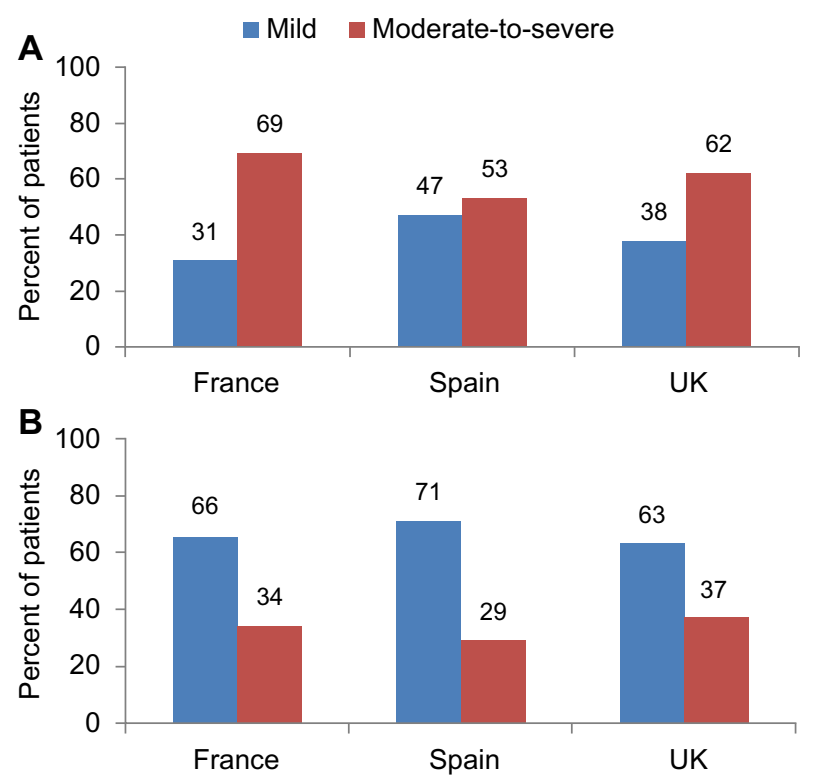

Figure I Distribution of psoriasis severity* in patients with (A) psoriatic arthritis and (B) psoriasis only.

Notes: *Severity was determined by PASI scores as described in the Materials and methods section. Distribution of mild versus moderate-to-severe disease was significantly different in patients with psoriatic arthritis than those with psoriasis only ( $P \leq 0.004$ for each country in chi-square tests). $n=I, 269$ for France, $55 I$ for Spain, and 507 for the UK.

Abbreviation: PASI, Psoriasis Area and Severity Index. related to disease severity were negatively associated with biologic treatment in the bivariate analyses, psoriatic arthritis was predictive of treatment with biologics in the regression model (statistically significant for Spain, numerically so for France), consistent with the greater disease severity observed in patients with psoriatic arthritis. According to Spanish guidelines, the presence of arthritis is a criterion for prescription of biologics. ${ }^{26}$ Because of the cross-sectional design of this study, we could not tell whether biologic use was the reason for lower PASI scores. We must speculate that the effectiveness of biologic therapy was at least part of the reason for the negative association.

To date there are no reliable predictors of response to tumor necrosis factor-alpha antagonists as a class (regardless of disease), ${ }^{27}$ and few studies have been performed to identify genetic predictors of response to biologics in psoriasis. ${ }^{28}$ Studies of variables associated with the clinical response of psoriatic arthritis to tumor necrosis factor-alpha antagonists have identified younger age ${ }^{29,30}$ and male sex..$^{29,31}$ In the present study, both age and female sex were not predictive of treatment with biologics.

Several limitations in this analysis stem from the data source. The data set refers to treatment patterns in 2007, which do not necessarily reflect current trends in biologic use. The proportions of patients seen in this study are not representative of psoriasis patients in general. The majority of mild-moderate patients are seen primarily by primary care practices. Further, as noted above, there was no documentation of prior failure to respond to conventional therapies. Data on PASI scores were not available for all patients. The paucity of PASI scores in the database required imputation of scores for most of the study population. As stated in the Materials and methods section, the correlation between actual and predicted PASI scores was moderate $(R=0.51)$. In addition, we observed no difference between 
actual and imputed mean PASI scores for patients treated with biologics versus patients treated with nonbiologics (including topicals only, phototherapy, and conventional systemic therapy).

In conclusion, an average of about one tenth of the psoriasis patients enrolled in this study in Spain, France, and the UK were treated with biologics. Physician-assessed moderate-to-severe disease and the presence of psoriatic arthritis were significantly predictive of biologic use in all three countries.

\section{Disclosure}

This study was supported by Merck and Co, Inc. The authors thank Lauren Weisenfluh and Melissa Stauffer, in collaboration with Scribco, for medical writing assistance. TF, QD, and NS are employees of Merck and Co, Inc. LP has no conflict of interest to report.

\section{References}

1. Nestle FO, Kaplan DH, Barker JN. Psoriasis. N Engl J Med. 2009;361: 496-509.

2. Pathirana D, Ormerod AD, Saiag P, et al. European S3-guidelines on the systemic treatment of psoriasis vulgaris. $J$ Eur Acad Dermatol Venereol. 2009;23 Suppl 2:1-70.

3. de Jong EM, Seegers BA, Gulinck MK, Boezeman JB, van de Kerkhof PC. Psoriasis of the nails associated with disability in a large number of patients: results of a recent interview with 1,728 patients. Dermatology. 1996;193(4):300-303.

4. Salomon J, Szepietowski JC, Proniewicz A. Psoriatic nails: a prospective clinical study. J Cutan Med Surg. 2003;7(4):317-321.

5. Augustin M, Reich K, Blome C, Schäfer I, Laass A, Radtke MA. Nail psoriasis in Germany: epidemiology and burden of disease. $\mathrm{Br} J$ Dermatol. 2010;163(3):580-585.

6. Prey S, Paul C, Bronsard V, et al. Assessment of risk of psoriatic arthritis in patients with plaque psoriasis: a systematic review of the literature. J Eur Acad Dermatol Venereol. 2010;24 Suppl 2: 31-35.

7. Augustin M, Reich K, Glaeske G, Schaefer I, Radtke M. Co-morbidity and age-related prevalence of psoriasis: analysis of health insurance data in Germany. Acta Derm Venereol. 2010;90(2):147-151.

8. Prey S, Paul C, Bronsard V, et al. Cardiovascular risk factors in patients with plaque psoriasis: a systematic review of epidemiological studies. J Eur Acad Dermatol Venereol. 2010;24 Suppl 2:23-30.

9. Dreiher J, Weitzman D, Davidovici B, Shapiro J, Cohen AD. Psoriasis and dyslipidaemia: a population-based study. Acta Derm Venereol. 2008;88(6):561-565.

10. Cohen AD, Weitzman D, Dreiher J. Psoriasis and hypertension: a casecontrol study. Acta Derm Venereol. 2010;90(1):23-26.

11. Tam LS, Tomlinson B, Chu TT, et al. Cardiovascular risk profile of patients with psoriatic arthritis compared to controls - the role of inflammation. Rheumatology. 2008;47(5):718-723.

12. Menter A, Korman NJ, Elmets CA, et al. Guidelines of care for the management of psoriasis and psoriatic arthritis. Section 5. Guidelines of care for the treatment of psoriasis with phototherapy and photochemotherapy. J Am Acad Dermatol. 2010;62(1):114-135.

13. European Medicines Agency. Ustekinumab (Stelara). Available from: http://www.ema.europa.eu/ema/index.jsp?curl=pages/medicines/human/ medicines/000958/human_med_001065.jsp\&murl=menus/medicines/ medicines.jsp\&jsenabled=true. Accessed December 5, 2013.
14. European Medicines Agency. Adalimumab (Humira). Available from: http://www.ema.europa.eu/ema/index.jsp?curl=pages/ medicines/human/medicines/000481/smops/Positive/human smop_000184.jsp\&murl=menus/medicines/medicines.jsp\&mid= WC0b01ac058001d127. Accessed December 5, 2013.

15. European Medicines Agency. Infliximab (Remicade). Available from: http://www.ema.europa.eu/ema/index.jsp?curl=pages/medicines/ human/medicines/000240/human_med_001023.jsp\&murl=menus/ medicines/medicines.jsp\&mid=WC0b01ac058001d124\&jsenabled $=\mathrm{t}$ rue. Accessed December 5, 2013.

16. European Medicines Agency. Etanercept (Enbrel). Available from: http:// www.ema.europa.eu/ema/index.jsp?curl=pages/medicines/human/ medicines/000262/human_med_000764.jsp\&mid=WC0b01ac058001d $125 \&$ murl=menus $/$ medicines $/$ medicines.jsp\&jsenabled=true. Accessed December 5, 2013.

17. Smith $\mathrm{CH}$, Anstey AV, Barker JN, et al. British Association of Dermatologists' guidelines for biologic interventions for psoriasis 2009. Br J Dermatol. 2009;161(5):987-1019.

18. Mrowietz U, Kragballe K, Reich K, et al. Definition of treatment goals for moderate-severe psoriasis: a European consensus. Arch Dermatol Res. 2011;303(1):1-10.

19. National Institute of Health and Clinical Excellence. Infliximab for the treatment of adults with psoriasis. 2008, NICE technology appraisal guidance 134. Available from: http://www.nice.org.uk/nicemedia/pdf/ ta134guidance.pdf. Accessed December 5, 2013.

20. Fredriksson T, Pettersson U. Severe psoriasis - oral therapy with a new retinoid. Dermatologica. 1978;157(4):238-244.

21. Augustin M, Reich K, Reich C, et al. Quality of psoriasis care in Germany - results of the national study PsoHealth 2007. J Dtsch Dermatol Ges. 2008;6(8):640-645.

22. Palota T, Szepietowski JC, Pec J, et al. A survey of disease severity, quality of life, and treatment patterns of biologically naive patients with psoriasis in central and eastern Europe. Acta Dermatovenerol Croat. 2010;18(3):151-161.

23. Kurd SK, Gelfand JM. The prevalence of previously diagnosed and undiagnosed psoriasis in US adults: results from NHANES 2003-2004. J Am Acad Dermatol. 2009;60(2):218-224.

24. Mahler R, Jackson C, Ijacu H. The burden of psoriasis and barriers to satisfactory care: results from a Canadian patient survey. J Cutan Med Surg. 2009;13(6):283-293.

25. Patel V, Horn EJ, Lobosco SJ, Fox KM, Stevens SR, Lebwohl M. Psoriasis treatment patterns: results of a cross-sectional survey of dermatologists. J Am Acad Dermatol. 2008;58(6):964-969.

26. Puig L, Carrascosa JM, Carretero G, et al. Spanish evidence-based guidelines on the treatment of psoriasis with biologic agents, 2013. Part 1: On efficacy and choice of treatment. Actas Dermosifiliogr. 2013;104(8):694-709.

27. Sfikakis PP. The first decade of biologic TNF antagonists in clinical practice: lessons learned, unresolved issues and future directions. Curr Dir Autoimmun. 2010;11:180-210.

28. Hébert HL, Ali FR, Bowes J, Griffiths CE, Barton A, Warren RB. Genetic susceptibility to psoriasis and psoriatic arthritis: implications for therapy. Br J Dermatol. 2012;166(3):474-482.

29. Glintborg B, Østergaard M, Dreyer L, et al. Treatment response, drug survival, and predictors thereof in 764 patients with psoriatic arthritis treated with anti-tumor necrosis factor alpha therapy: results from the nationwide Danish DANBIO registry. Arthritis Rheum. 2011;63(2): 382-390.

30. Iervolino S, Di Minno MN, Peluso R, et al. Predictors of early minimal disease activity in patients with psoriatic arthritis treated with tumor necrosis factor-alpha blockers. J Rheumatol. 2012;39(3): 568-573.

31. Van den Bosch F, Manger B, Goupille P, et al. Effectiveness of adalimumab in treating patients with active psoriatic arthritis and predictors of good clinical responses for arthritis, skin and nail lesions. Ann Rheum Dis. 2010;69(2):394-399. 


\section{Publish your work in this journal}

ClinicoEconomics \& Outcomes Research is an international, peerreviewed open-access journal focusing on Health Technology Assessment, Pharmacoeconomics and Outcomes Research in the areas of diagnosis, medical devices, and clinical, surgical and pharmacological intervention. The economic impact of health policy and health systems

organization also constitute important areas of coverage. The manuscript management system is completely online and includes a very quick and fair peer-review system, which is all easy to use. Visit http://www.dovepress.com/testimonials.php to read real quotes from published authors.

Submit your manuscript here: http://www.dovepress.com/clinicoeconomics-and-outcomes-research-journal 